\title{
Peripheral and central effects of $\gamma$-secretase inhibition by semagacestat in Alzheimer's disease
}

\author{
Rachelle S Doody ${ }^{1}$, Rema Ramann ${ }^{2,3}$, Reisa A Sperling ${ }^{4}$, Eric Seimers ${ }^{5}$, Gopalan Sethuraman ${ }^{5}$, Richard Mohs ${ }^{5}$, \\ Martin Farlow ${ }^{6}$, Takeshi Iwatsubo ${ }^{7}$, Bruno Vellas ${ }^{8}$, Xiaoying Sun ${ }^{9}$, Karin Ernstrom ${ }^{9}$, Ronald G Thomas ${ }^{3,10}$, \\ and Paul S Aisen ${ }^{3^{*}}$ for the Alzheimer's Disease Cooperative Study
}

\begin{abstract}
Introduction: The negative efficacy study examining the $\gamma$-secretase inhibitor semagacestat in mild to moderate Alzheimer's disease (AD) included a number of biomarkers of the disease as well as safety outcomes. We analyzed these data to explore relationships between drug exposure and pharmacodynamic effects and to examine the correlations among outcome measures.

Methods: The study was a multicenter, randomized, placebo-controlled trial of two dose regimens of semagacestat and a placebo administered for 18 months to individuals with mild to moderate AD. Changes in measures of central and peripheral drug activity were compared between the three treatment groups using one-way analysis of variance. The relationship between changes in each of the outcome measures and measures of drug exposure and peripheral pharmacodynamic effect were assessed using Spearman's correlation coefficient.

Results: Assignment to the active treatment arms was associated with reduction in plasma amyloid- $\beta$ (A $\beta$ ) peptides, increase in ventricular volume, decrease in cerebrospinal fluid phosphorylated tau ( $p$-tau) and several other laboratory measures and adverse event categories. Within the active arms, exposure to drug, as indicated by area under the concentration curve (AUC) of blood concentration, was associated with reduction in plasma A $\beta$ peptides and a subset of laboratory changes and adverse event rates. Ventricular volume increase, right hippocampal volume loss and gastrointestinal symptoms were related to change in plasma A $\beta$ peptide but not AUC, supporting a link to inhibition of $\gamma$-secretase cleavage of the amyloid precursor protein. Cognitive decline correlated with ventricular expansion and reduction in p-tau.
\end{abstract}

Conclusion: These findings may inform future studies of drugs targeting secretases involved in A $\beta$ generation.

Trial registration: ClinicalTrials.gov Identifier: NCT00594568. Registered 11 January 2008.

\section{Introduction}

One leading theory of the pathogenesis of Alzheimer's disease $(\mathrm{AD})$ considers the sequential cleavage of the amyloid precursor protein (APP) by $\beta$ - and $\gamma$-secretases to release amyloidogenic peptides to be the initiating and driving event in this neurodegenerative condition [1]. Inhibition of secretases has therefore been a major strategy in efforts to develop disease-modifying treatments for AD [2]. The strategy of $\gamma$-secretase inhibition to slow disease progression is further supported by the finding that the most common mutations that cause

\footnotetext{
* Correspondence: paisen@ucsd.edu

${ }^{3}$ Department of Neurosciences, University of California San Diego, 9500

Gilman Drive, M/C 0949, La Jolla, CA 92093, USA

Full list of author information is available at the end of the article
}

familial autosomal dominant AD involve presenilin, a $\gamma$-secretase component [3].

The first large-scale study of a $\gamma$-secretase modulating drug, flurbiprofen, was ineffective [4]. This failure has been attributed to insufficient pharmacodynamic effects in the brain. More recently, novel $\gamma$-secretase inhibitors have demonstrated target engagement, as indicated by reduction in cerebrospinal fluid (CSF) levels of amyloid peptides [5,6]. A major concern about this drug class has been adverse effects related to impact on non-target substrates [6-8]. In particular, Notch cleavage by $\gamma$-secretase may be inhibited by such drugs [9], with adverse effects on the gastrointestinal, immune and cutaneous systems.

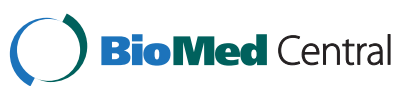

(C) 2015 Doody et al.; licensee BioMed Central. This is an Open Access article distributed under the terms of the Creative Commons Attribution License (http://creativecommons.org/licenses/by/4.0), which permits unrestricted use, distribution, and reproduction in any medium, provided the original work is properly credited. The Creative Commons Public Domain Dedication waiver (http://creativecommons.org/publicdomain/zero/1.0/) applies to the data made available in this article, unless otherwise stated. 
Semagacestat is generally referred to as a $\gamma$-secretase inhibitor, but we note that it increases levels of amyloid$\beta$ peptide 42 (A $\beta 42)$ in the blood at low concentrations, suggesting that it may exert its activity at an allosteric site rather than the active site of the enzyme. It does not increase generation of shorter peptides (such as A 338 ), which is a characteristic of drugs referred to as $\gamma$-secretase modulators.

Semagacestat was the first $\gamma$-secretase inhibitor to reach Phase III testing in AD. The development of this drug was spurred by strong evidence for a central pharmacodynamic effect in a study in which researchers used stable isotope labeling with CSF sampling to determine the kinetics of amyloid peptide production [7]. The phase III trial, the primary results of which are reported elsewhere [10], was terminated before planned completion because of evidence of cognitive and other adverse effects in the active treatment group. Data derived from the trial afford an opportunity to evaluate the peripheral laboratory and clinical effects and the central effects of $\gamma$-secretase inhibition in AD. This experience may inform other ongoing efforts to target this enzyme complex.

\section{Methods}

\section{Patients, drug dosing and blinding}

The present study was approved by the institutional review boards at each participating site (see Additional file 1). Subjects aged 55 years or older with mild to moderate AD (Mini Mental State Examination (MMSE) [11] score between 16 and 26 at screening) who met National Institute of Neurological and Communicative Disorders and Stroke/ Alzheimer's Disease and Related Disorders Association criteria [12] and were in good general health and free of depression (Geriatric Depression Scale score $\leq 6$ ) [13]) were randomized to escalate to $100 \mathrm{mg}$ once daily or $140 \mathrm{mg}$ once daily of semagacestat or placebo over 76 weeks using a triple dummy to blind dosage groups. Doses were titrated as follows: $60 \mathrm{mg}$ for 2 weeks, then $100 \mathrm{mg}$; or $60 \mathrm{mg}$ for 2 weeks, $100 \mathrm{mg}$ for 2 weeks, then $140 \mathrm{mg}$. At baseline, subjects could be untreated or treated with background cholinesterase inhibitors with or without memantine, as long as they had been on the drug for at least 4 weeks and the doses of antidementia drugs were stable for at least 2 months. All subjects signed informed consent forms prior to participating in study procedures.

\section{Cognitive measures}

Patients were assessed with the 11-item version of the Alzheimer's Disease Assessment Scale-Cognitive Subscale (ADAScog11) [14] at baseline and weeks 12, 28, 40, 52, 64,76 and 88 or at early termination and with the MMSE at screening, baseline and weeks 52, 76 and 88 or early termination.

\section{Biological markers and imaging outcome measures}

Patients were genotyped for apolipoprotein E polymorphisms. Special lymphocyte hematology was done at baseline and weeks $12,28,40,52,64,76$ and 88 or early termination. Plasma A $\beta$ was assessed at baseline and weeks 6,12 and 52 or early termination. Optional CSF analysis for $A \beta$ peptides and tau and phosphorylated tau (p-tau) proteins was conducted in willing subjects. Volumetric magnetic resonance imaging (vMRI), amyloid imaging with florbetapir (AV45) fludeoxyglucose positron emission tomography (FDG-PET), and CSF analyses were performed at baseline and week 76 or early termination. Additional details regarding methods are provided in the Appendix to the article describing the primary results of the phase III trial [10].

\section{Pharmacokinetic measures}

Pharmacokinetic (PK) samples were collected at week 6, 12 and 52. Population PK analysis was performed using a nonlinear mixed-effects model. The model estimated individual clearance values for each subject using all concentrations collected at each visit, taking into account time from dose, the dose level administered, and estimated residual error that resulted from assay error, inaccurate sample time information or inaccurate dosing information. The clearance estimate for each individual was used to calculate area under the concentration curve (AUC) using standard equations. A similar process was undertaken to generate maximum concentration $\left(\mathrm{C}_{\max }\right)$ using standard equations to calculate $\mathrm{C}_{\max }$ and individual estimates for various PK parameters.

\section{Alzheimer's Disease Cooperative Study Data Analysis and Publication Committee}

The Data Analysis and Publication Committee (DAPC) was funded by a grant from Eli Lilly to the University of California at San Diego as fiduciary for the Alzheimer's Disease Cooperative Study (ADCS) after the semagacestat phase III studies were halted, but before the datasets were transferred to the ADCS. The timing of the contract was designed to remove any concern that payment for the work of data analysis and publication would be dependent upon the outcome. The DAPC developed a document of governance that specifies voting members of the committee, as well as non-voting members, who include a limited number of Eli Lilly employees who are familiar with the study and the data and one non-voting representative each of the Data Safety Monitoring Committee and the National Institute on Aging. The DAPC also developed a data dissemination plan and kept the ADCS Steering Committee apprised of its progress by formal reports at each Steering Committee meeting. The final publication was developed by the committee and approved by the voting members of the 
DAPC committee and the ADCS steering committee, and non-voting DAPC members gave feedback but did not have veto power.

\section{Statistical analysis}

Changes in outcome measures reflecting central and peripheral activity of semagacestat were compared between the three treatment groups using one-way analysis of variance. Analyses included all randomized subjects with available data. Annualized change from baseline in cognitive, CSF and three imaging outcomes (vMRI, FDG-PET and AV45) were calculated based on the last available observation in the initial treatment period. The outcome for plasma $A \beta$ used percentage change from baseline to 6 hours postdose at week 52. Laboratory measures included change from baseline in uric acid, albumin and eosinophils at week 76 . Specific adverse events, including gastrointestinal, skin disorder, skin cancer and infection incidence, were compared between the three treatment groups using the Fisher-Freeman-Halton exact test. The relationship between change in each of the outcome measures (cognitive tests, plasma A $\beta$, CSF assays, vMRI, FDG-PET and rates of specific adverse events) and measures of drug exposure (AUC in the active treatment group) and peripheral pharmacodynamic effects (changes in plasma $A \beta$ ) were assessed using Spearman's correlation coefficient [15]. R version 2.14.1 statistical software [16] was used for all statistical analyses. We did not employ corrections for multiple comparisons in this exploratory analysis.

\section{Results}

\section{Outcomes by treatment group}

Summary statistics of key outcomes are shown in Table 1 for the three arms of the trial. Treatment assignment was associated with ventricular volume (greater ventricular expansion in high-dose arm), CSF p-tau (increase in placebo arm, reduction in treatment arms), plasma $A \beta$ peptides (dose-related reduction in active arms) and several laboratory measures and adverse event categories (Table 1). The relationship between arm assignment and change in plasma $A \beta$ peptides is shown in Figure 1. Levels of both species of amyloid peptide had declined in both active treatment arms by week 6 , and the reductions were sustained until week 52 (the final analysis time point for plasma amyloid peptides).

Table 1 Outcomes by treatment arms ${ }^{a}$

\begin{tabular}{|c|c|c|c|c|}
\hline & Placebo & LY $100 \mathrm{mg}$ & LY $140 \mathrm{mg}$ & $P$-value \\
\hline Annualized change in ADASCog11 & $4.75 \pm 21.92(n=485)$ & $6.57 \pm 25.57(n=482)$ & $5.48 \pm 21.92(n=495)$ & 0.408 \\
\hline Annualized change in MMSE & $-2.19 \pm 3.65(n=396)$ & $-2.56 \pm 3.65(n=324)$ & $-2.92 \pm 3.65(n=303)$ & 0.159 \\
\hline Annualized change in FDG-PET SUVR & $-0.06 \pm 0.07(n=40)$ & $-0.13 \pm 0.21(n=42)$ & $-0.1 \pm 0.08(n=33)$ & 0.109 \\
\hline Annualized change in AV45 SUVR & $0.05 \pm 0.11(n=18)$ & $0.02 \pm 0.24(n=23)$ & $0.07 \pm 0.23(n=18)$ & 0.794 \\
\hline Annualized change in ventricular volume & $4.07 \pm 3.52(n=80)$ & $4.19 \pm 3.92(n=74)$ & $5.68 \pm 4.68(n=67)$ & 0.033 \\
\hline Annualized change in right hippocampal volume & $-86.28 \pm 73.86(n=74)$ & $-91.08 \pm 102.1(n=68)$ & $-90.98 \pm 71.1(n=64)$ & 0.926 \\
\hline Annualized change in left hippocampal volume & $-68.85 \pm 59.01(n=74)$ & $-70.4 \pm 90.81(n=68)$ & $-91.0 \pm 101.2(n=64)$ & 0.244 \\
\hline Annualized change in CSF A 440 & $87.66 \pm 847(n=10)$ & $-10.96 \pm 1151(n=19)$ & $-599 \pm 1786(n=18)$ & 0.328 \\
\hline Annualized change in CSF A 342 & $10.96 \pm 87.66(n=10)$ & $-40.18 \pm 109.6(n=19)$ & $-36.5 \pm 182.7(n=18)$ & 0.619 \\
\hline Annualized change in p-tau & $10.96 \pm 7.31(n=10)$ & $-7.31 \pm 14.61(n=19)$ & $-3.65 \pm 10.96(n=18)$ & 0.009 \\
\hline Annualized change in total tau & $94.97 \pm 116.9(n=10)$ & $-43.83 \pm 219.2(n=17)$ & $40.18 \pm 127.8(n=18)$ & 0.101 \\
\hline Percentage change in plasma $A \beta 40$ at week 52 & $4.77 \pm 26.67(n=307)$ & $-37.54 \pm 109.3(n=264)$ & $-47.76 \pm 32.06(n=243)$ & $<0.001$ \\
\hline Percentage change in plasma $A \beta 42$ at week 52 & $3.82 \pm 20.75(n=309)$ & $-5.4 \pm 53.1(n=265)$ & $-18.14 \pm 33.0(n=245)$ & $<0.001$ \\
\hline Change in uric acid at week 76 & $0.18 \pm 0.83(n=210)$ & $-0.96 \pm 1.08(n=179)$ & $-0.88 \pm 1.22(n=147)$ & $<0.001$ \\
\hline Change in albumin at week 76 & $0 \pm 0.25(n=210)$ & $-0.09 \pm 0.31(n=179)$ & $-0.09 \pm 0.3(n=147)$ & 0.002 \\
\hline Change in eosinophils at week 76 & $-0.001 \pm 0.09(n=207)$ & $0.05 \pm 0.17(n=179)$ & $0.06 \pm 0.14(n=143)$ & $<0.001$ \\
\hline Gastrointestinal symptoms & $153(31.5 \%)$ & $169(34.9 \%)$ & $193(38.8 \%)$ & 0.057 \\
\hline Skin disorder incidence & $105(21.6 \%)$ & $220(45.4 \%)$ & $269(54 \%)$ & $<0.001$ \\
\hline Skin cancer incidence & $8(1.7 \%)$ & $51(10.5 \%)$ & $56(11.2 \%)$ & $<0.001$ \\
\hline Infection incidence & $156(32.1 \%)$ & $188(38.8 \%)$ & $220(44.2 \%)$ & $<0.001$ \\
\hline AUC & & $5,316 \pm 1,525(n=480)$ & $7,235 \pm 2233(n=494)$ & $<0.001$ \\
\hline$C_{\max }$ & & $1,105 \pm 260(n=480)$ & $1,508 \pm 384(n=494)$ & $<0.001$ \\
\hline
\end{tabular}

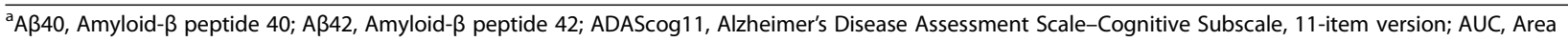
under the curve; AV45, Florbetapir; $C_{\max }$, Maximum concentration; CSF, Cerebrospinal fluid; FDG-PET, Fludeoxyglucose positron emission tomography; LY, Semagacestat; MMSE, Mini Mental State Examination; p-tau, Phosphorylated tau; SUVR, Standard uptake value ratio. 

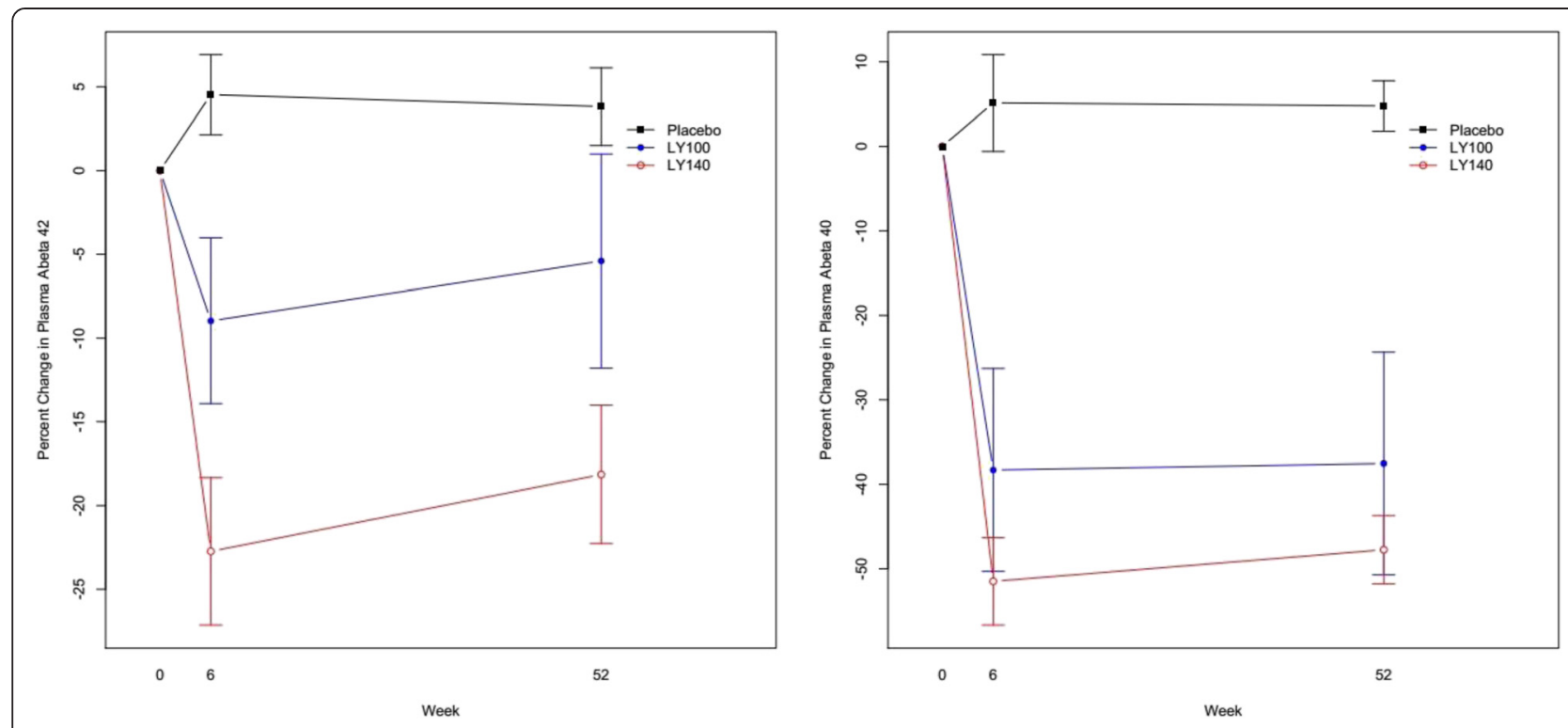

Figure 1 Change in plasma amyloid- $\beta$ peptide levels. Abeta, Amyloid- $\beta$; LY100mg, Semagacestat 100 mg; LY140mg, Semagacestat 140 mg

As expected, the mean $\mathrm{AUC}$ and $\mathrm{C}_{\max }$ increased with increasing dose, although there was overlap between the dose groups.

\section{Correlational analyses}

Among adverse events, correlational analyses suggested that gastrointestinal symptoms, rash and skin cancer may be related to each other, while uric acid reduction, albumin reduction and infection formed a cluster (Table 2). Among markers of central nervous system effects, decline in cognition measured either by increase in ADAScog 11 score or decrease in MMSE score correlated with each other and with ventricular expansion (Table 3). Consistent with the overall groupwise effects, there was an unexpected correlation between reduction in CSF p-tau and cognitive decline.

To determine whether clinical and laboratory effects were more closely associated with drug exposure or with the target pharmacodynamic effects (inhibition of $\gamma$-secretase cleavage of the APP to release amyloidogenic peptides), we examined the correlation between measures and semagacestat AUC and change in plasma $A \beta 40$, respectively (Table 4). We used $A \beta 40$ rather than $A \beta 42$ because the latter values were confounded in some cases by measurement below the level of detection.

Uric acid reduction was correlated to drug exposure but not to plasma $A \beta$ change, suggesting a mechanism distinct from inhibition of APP cleavage such as druginduced Fanconi syndrome. Reduction in serum albumin and increase in eosinophil counts correlated with both AUC and reduction in plasma $A \beta$. There was a trend relating decrease in FDG PET SUVR to AUC, but no relationship with change in plasma $A \beta$ reducing the likelihood that the proposed pharmacological mechanism of the drug influenced FDG signal. In contrast, gastrointestinal symptoms were related to plasma $A \beta$

Table 2 Correlations between peripheral biomarkers ${ }^{a}$

\begin{tabular}{|c|c|c|c|c|c|c|c|c|c|}
\hline & AUC & Plasma $A \beta 40$ & Uric acid & Albumin & EOS & GI & Skin & Skin cancer & Infection \\
\hline AUC & $1 ; 0$ & $-0.36 ; 0.001$ & $-0.15 ; 0.007$ & $-0.14 ; 0.01$ & $0.18 ; 0.001$ & $0.02 ; 0.65$ & $-0.02 ; 0.63$ & $-0.01 ; 0.81$ & $0.14 ; 0.001$ \\
\hline Plasma A $\beta 40$ & & $1 ; 0$ & $-0.01 ; 0.86$ & $0.131 ; 0.03$ & $-0.19 ; 0.002$ & $-0.10 ; 0.03$ & $-0.08 ; 0.06$ & $-0.08 ; 0.09$ & $-0.07 ; 0.11$ \\
\hline Uric acid & & & $1 ; 0$ & $0.08 ; 0.13$ & $-0.23 ; 0.001$ & $0.03 ; 0.60$ & $-0.12 ; 0.04$ & $-0.08 ; 0.13$ & $-0.11 ; 0.04$ \\
\hline Albumin & & & & $1 ; 0$ & $-0.22 ; 0.001$ & $0.05 ; 0.42$ & $0.02 ; 0.72$ & $0.02 ; 0.68$ & $-0.15 ; 0.006$ \\
\hline EOS & & & & & $1 ; 0$ & $-0.01 ; 0.85$ & $0.04 ; 0.50$ & $0.11 ; 0.06$ & $0.08 ; 0.17$ \\
\hline Gl & & & & & & $1 ; 0$ & $0.11 ; 0.001$ & $0.05 ; 0.16$ & $0.17 ; 0.001$ \\
\hline Skin & & & & & & & $1 ; 0$ & $0.14 ; 0.001$ & $0.13 ; 0.001$ \\
\hline Skin cancer & & & & & & & & $1 ; 0$ & $0.123 ; 0.001$ \\
\hline Infection & & & & & & & & & $1 ; 0$ \\
\hline
\end{tabular}

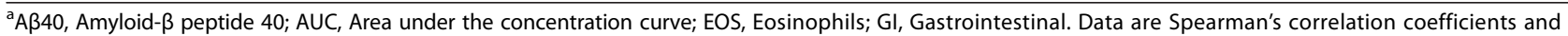
$P$-values $(r ; P)$. 
Table 3 Correlations between changes in central biomarkers ${ }^{a}$

\begin{tabular}{llllll}
\hline & Ventricular volume & CSF p-tau & CSF A 342 & ADAScog11 & MMSE \\
\hline FDG-PET SUVR & $-0.43 ; 0.007$ & $-0.14 ; 0.79$ & $0.37 ; 0.47$ & $-0.11 ; 0.36$ & $0.23 ; 08$ \\
Ventricular volume & $1 ; 0$ & $-0.14 ; 0.62$ & $-0.12 ; 0.67$ & $0.46 ; 0.001$ & $-0.54 ; 0.001$ \\
CSF p-tau & & $1 ; 0$ & $0.37 ; 0.49$ & $-0.40 ; 0.02$ & $0.33 ; 0.05$ \\
CSF A 42 & & $1 ; 0$ & $-0.12 ; 0.48$ & $0.31 ; 0.08$ \\
ADAScog11 & & & & $1 ; 0$ & $-0.58 ; 0.001$ \\
\hline
\end{tabular}

${ }^{a} A \beta 42$, Amyloid- $\beta$ peptide 42; ADAScog11, Alzheimer's Disease Assessment Scale-Cognitive Subscale, 11 -item version; CSF, Cerebrospinal fluid; FDG-PET, Fludeoxyglucose positron emission tomography; MMSE, Mini Mental State Examination; p-tau, Phosphorylated tau; SUVR, Standard uptake value ratio. Data are Spearman's correlation coefficients and $P$-values $(r ; P)$.

change but not to drug exposure, consistent with a shared mechanism related to $\gamma$-secretase cleavage of APP. Of note, MRI volumetric change, specifically atrophy as indicated by increase in ventricular volume, was also correlated to change in plasma $A \beta$. Because drug exposure and change in plasma $A \beta 40$ are strongly correlated, adjusting the correlations of each with the other generally reduces the association of each measure; however, the relationship between change in plasma $A \beta 40$ and ventricular volume and right hippocampal volume were essentially unaffected by adjustment for AUC.

\section{Discussion}

Semagacestat reduced plasma levels of $A \beta$ peptides, consistent with $\gamma$-secretase inhibition in the periphery. The absence of an effect on CSF A $\beta$ peptide levels was consistent with the findings in the phase II trial [17] and may have been related to the small numbers of lumbar punctures and their timing in relation to dosing $[7,17]$. Thus, unlike our previous study in which we used the stable isotope labeling kinetic technique [7], the available data from this trial do not confirm adequate target engagement in the central nervous system, clouding interpretation of the results.

The most notable central nervous system effect was an adverse effect on cognition in the high-dose arm, leading to early termination of the trial, and a reduction in change in CSF p-tau in the active arms compared with placebo [10]. The p-tau effect is difficult to interpret. Although it is consistent with a possible beneficial effect on disease pathology, suggesting a link between $A \beta$

Table 4 Correlations of change in selected outcome measures with drug exposure and reduction in plasma amyloid- $\beta$ peptide 40 in the active arms ${ }^{a}$

\begin{tabular}{|c|c|c|c|c|c|c|c|c|c|c|c|c|}
\hline & \multicolumn{3}{|c|}{ Semagacestat AUC } & \multicolumn{3}{|c|}{$\begin{array}{l}\text { Change in plasma } \\
A \beta 40\end{array}$} & \multicolumn{3}{|c|}{$\begin{array}{l}\text { AUC adjusted for } \\
A \beta 40\end{array}$} & \multicolumn{3}{|c|}{$\begin{array}{l}\text { A } \beta 40 \text { adjusted for } \\
\text { AUC }\end{array}$} \\
\hline & $r$ & $\mathbf{n}$ & $P$ & $r$ & $\mathrm{n}$ & $P$ & $r$ & $\mathrm{n}$ & $P$ & $r$ & $\mathrm{n}$ & $P$ \\
\hline Change in uric acid at week 76 & -0.151 & 320 & 0.007 & 0.011 & 263 & 0.857 & -0.149 & 260 & 0.016 & 0.071 & 260 & 0.255 \\
\hline Change in albumin at week 76 & -0.14 & 320 & 0.012 & -0.131 & 263 & 0.033 & -0.037 & 260 & 0.548 & -0.107 & 260 & 0.084 \\
\hline Gastrointestinal symptoms & 0.015 & 943 & 0.654 & 0.099 & 507 & 0.025 & -0.004 & 501 & 0.933 & 0.094 & 501 & 0.034 \\
\hline Skin disorder incidence & 0.016 & 943 & 0.627 & 0.083 & 507 & 0.062 & -0.048 & 501 & 0.279 & 0.096 & 501 & 0.031 \\
\hline Skin cancer incidence & -0.012 & 943 & 0.71 & 0.075 & 507 & 0.091 & -0.039 & 501 & 0.389 & 0.084 & 501 & 0.059 \\
\hline Infection incidence & 0.136 & 943 & $<0.001$ & 0.072 & 507 & 0.101 & 0.068 & 501 & 0.129 & 0.042 & 501 & 0.344 \\
\hline Annualized change in FDG SUVR & 0.22 & 74 & 0.06 & $<0.001$ & 48 & 0.998 & 0.357 & 48 & 0.010 & -0.134 & 48 & 0.364 \\
\hline Annualized change in ventricular volume & 0.003 & 139 & 0.97 & 0.242 & 91 & 0.021 & -0.109 & 91 & 0.302 & 0.264 & 91 & 0.010 \\
\hline Annualized change in right hippocampal volume & -0.064 & 130 & 0.472 & -0.264 & 86 & 0.014 & -0.039 & 86 & 0.719 & -0.222 & 86 & 0.038 \\
\hline Annualized change in left hippocampal volume & -0.109 & 130 & 0.216 & -0.036 & 86 & 0.74 & -0.167 & 86 & 0.123 & 0.043 & 86 & 0.697 \\
\hline Annualized change in AV45 SUVR & 0.133 & 40 & 0.414 & 0.316 & 27 & 0.109 & -0.079 & 27 & 0.697 & 0.324 & 27 & 0.093 \\
\hline Annualized change in ADASCog11 & -0.012 & 938 & 0.707 & 0.037 & 505 & 0.403 & -0.080 & 499 & 0.074 & 0.060 & 499 & 0.177 \\
\hline Annualized change in MMSE & 0.038 & 618 & 0.351 & -0.019 & 496 & 0.678 & 0.057 & 490 & 0.211 & -0.037 & 490 & 0.414 \\
\hline Annualized change in p-tau & 0.02 & 37 & 0.909 & -0.124 & 33 & 0.491 & 0.101 & 33 & 0.578 & -0.154 & 33 & 0.395 \\
\hline Annualized change in total tau & 0.07 & 35 & 0.691 & 0.003 & 31 & 0.986 & -0.017 & 31 & 0.930 & 0.010 & 31 & 0.957 \\
\hline Annualized change in CSF A 442 & -0.13 & 37 & 0.443 & 0.152 & 33 & 0.399 & -0.103 & 33 & 0.571 & 0.179 & 33 & 0.318 \\
\hline
\end{tabular}

${ }^{a}$ A $\beta 40$, Amyloid- $\beta$ peptide 40; A 342 , Amyloid- $\beta$ peptide 42; ADAScog11, Alzheimer's Disease Assessment Scale Cognitive Subscale, 11 -item version; AUC, Area under the concentration curve; AV45, Florbetapir; CSF, Cerebrospinal fluid; FDG-PET, Fludeoxyglucose positron emission tomography; MMSE, Mini Mental State Examination; p-tau, Phosphorylated tau; SUVR, Standard uptake value ratio. 
peptide production and downstream tau abnormalities, the fact that p-tau decreases have been found in longitudinal studies of AD [18] could also mean that this finding was associated with increased neurodegeneration due to accelerated disease. The worsening of cognition in the face of these findings suggests that a substrate of $\gamma$-secretase other than APP may have been responsible for the cognitive effects. However, p-tau increased in the placebo group more than it decreased in the treated group, which may point to some instability in the assay. In contrast, the correlational studies link the drugrelated change in plasma $A \beta$ to increased brain atrophy. Whereas such atrophy has been associated with antiamyloid immunotherapy and could be related to reduction in inflammation or other effects of amyloid removal, the present data link atrophy to an adverse effect on cognition consistent with a deleterious pharmacological effect on the disease process. Further, it must be emphasized that these analyses do not establish causality and are confounded by dependence among the various measures.

Similar adverse effects have been reported with another $\gamma$-secretase inhibitor, avagacestat [6]. Specifically, gastrointestinal and skin rash findings, non-melanoma skin cancer and worsening cognition at higher doses were observed with that drug, strongly supporting a link to $\gamma$-secretase inhibition. The development of semagacestat $[19,20]$ has been discontinued. A number of research groups continue to pursue $\gamma$-secretase modulation and $\beta$-site APP-cleaving enzyme 1 (or BACE) inhibition as alternative, perhaps safer, routes to reduction of amyloid peptide production.

If the adverse effects are related to off-target substrates, $\gamma$-secretase modulators, which do not act at the active site of the enzyme complex and do not interfere with cleavage of non-APP substrates, may not carry these risks. But the correlational analyses seem more consistent with a direct relationship among adverse clinical effects, increase in atrophy, cognitive decline and possibly p-tau reduction.

There were correlations among peripheral and central measures of drug level and activity and adverse effects on cognition, consistent with related mechanisms. However, causality cannot be inferred; each of these effects is related to drug exposure, so correlations among them are expected. Observed drug effects could be related to inhibition of cleavage of substrates other than APP. Semagacestat is a non-specific inhibitor of $\gamma$-secretase, and the half-maximal effective concentration $\left(\mathrm{EC}_{50}\right)$ for inhibition of Notch cleavage has been reported to be similar to that for APP cleavage [21]; other methods have indicated a tenfold stronger inhibition of Notch cleavage [22]. Presumably, the $\mathrm{EC}_{50}$ of semagacestat for other transmembrane proteins that are substrates for $\gamma$-secretase may be in the same range. On the basis of the clinical trial results alone, the question could be raised whether a lower dose of semagacestat given twice daily might have been better tolerated; however, toxicology studies using beagle dogs and rats showed that the same total daily dose of semagacestat was tolerated very poorly when divided into twice daily dosing due to findings consistent with Notch-mediated gastroenteropathy (data on file, Eli Lilly \& Company). It also remains possible that inhibition of $\gamma$-secretase cleavage of APP is related to the adverse effect on cognition observed in the high-dose arm of this trial. Further studies of $\gamma$-secretase inhibitors and modulators should include monitoring for adverse systemic and cognitive effects.

Progression of AD is characterized by decline in cognitive performance and atrophy of brain tissue. In the semagacestat trial, high-dose treatment had an adverse effect on cognition [10], and in the present analyses, cognitive decline was related to expansion of ventricular volume. The relationship between reduction in CSF p-tau and worsening cognition among those treated with semagacestat cannot be readily explained with the available data. Treatment effects on cognitive and biomarker measures in $\mathrm{AD}$ may not be predicted by the patterns of longitudinal change noted in observational studies. Elucidation of the mechanisms of these discordant effects will require data derived from additional trials of various therapeutic interventions, as well as more longitudinal data on biomarker changes in mild to moderate AD.

\section{Conclusions}

Analysis of the relationships among PK/pharmacodynamic measures, biomarkers and laboratory tests in the phase III trial of semagacestat in mild to moderate $\mathrm{AD}$ provides some insight into the neurobiological and clinical impact of $\gamma$-secretase inhibition. Exposure to drug was associated with reduction in plasma $\mathrm{A} \beta$ peptides, as well as a subset of laboratory changes and adverse event rates. Measures of brain atrophy and gastrointestinal symptoms were related to changes in plasma $A \beta$ peptide but not drug concentration, supporting a link to inhibition of $\gamma$-secretase cleavage of the APP. Cognitive decline correlated with ventricular expansion and reduction in p-tau. These findings may be useful to future investigators in the design of studies targeting secretases involved in $A \beta$ generation.

\section{Additional file}

Additional file 1: Ethical review board information and informed

consent document.

\section{Abbreviations}

ADAScog11: Alzheimer's Disease Assessment Scale-Cognitive Subscale, 11-item version; A $\beta$ : Amyloid- $\beta$; AUC: Area under the concentration curve;

AD: Alzheimer's disease; ADCS: Alzheimer's Disease Cooperative Study; 
APP: Amyloid precursor protein; AV45: Florbetapir; $C_{\text {max }}$ : Maximum concentration; CSF: Cerebrospinal fluid; DAPC: Data Analysis and Publication Committee; $\mathrm{EC}_{50}$ : Half-maximal effective concentration; EOS: Eosinophils; FDG-PET: Fludeoxyglucose positron emission tomography;

GI: Gastrointestinal; LY: Semagacestat; MMSE: Mini Mental State Examination; PK: Pharmacokinetic; p-tau: Phosphorylated tau; SUVR: Standard uptake value ratio; vMRI: Volumetric magnetic resonance imaging.

\section{Competing interests}

ES, GS and RM are full-time employees of Eli Lilly. RSD, RR, MF, TI, BV, XS, KE, RGT and PSA received financial support in advance from Eli Lilly through the Data and Publications Committee of the Alzheimer's Disease Cooperative Study. No non-financial competing interests exist for any of the authors.

\section{Authors' contributions}

PSA drafted the manuscript. RSD, RR, RS, ES, GS, RM, MF, TI, BV, XS, KE, RGT and PSA contributed to the interpretation of data and revision of the manuscript. RR, XS, KE and RGT performed the statistical analyses. All authors read and approved the final manuscript.

\section{Acknowledgements}

The phase III semagacestat study was funded and conducted by Eli Lilly. The Alzheimer's Disease Cooperative Study (ADCS) is funded by the National Institute on Aging of the National Institutes of Health. The ADCS Data and Publications Committee was supported by advance funding from Eli Lilly.

\begin{abstract}
Author details
${ }^{1}$ Alzheimer's Disease and Memory Disorders center, Department of Neurology, Baylor College of Medicine, 1977 Butler Blvd, Suite E5.101, Houston, TX, USA. ${ }^{2}$ Division of Biostatistics and Bioinformatics, Department of Family and Preventive Medicine, Department of Neurosciences, University of California San Diego, 9500 Gilman Drive, M/C 0949, La Jolla, CA 92093, USA. ${ }^{3}$ Department of Neurosciences, University of California San Diego, 9500 Gilman Drive, M/C 0949, La Jolla, CA 92093, USA. ${ }^{4}$ Department of Neurology, Harvard Medical School, 220 Longwood Avenue, Goldenson Building, Room 420, Boston, MA 02115, USA. ${ }^{5}$ Eli Lilly \& Company, Lilly Corporate Center, Indianapolis, IN 46285, USA. ${ }^{6}$ Department of Neurology, Indiana University, Indiana Alzheimer Disease Center, 355 W. 16th Street, Suite 4700, Indianapolis, IN 46202, USA. ${ }^{7}$ Graduate School of Medicine, University of Tokyo, 7-3-1, Hongo, Bunkyo-ku, Tokyo 113-8654, Japan. ${ }^{8}$ Gerontopole UMR INSERM 1027, CHU, University of Toulouse, Toulouse, France. ${ }^{9}$ Biostatistics Research Center, Department of Family and Preventive Medicine, University of California San Diego, 9500 Gilman Drive, M/C 0949, La Jolla, CA 92093, USA. ${ }^{10}$ Alzheimer's Disease Cooperative Study, Department of Family and Preventive Medicine, Department of Neurosciences, University of California San Diego, 9500 Gilman Drive M/C 0949, La Jolla, CA 92093, USA.
\end{abstract}

Received: 15 August 2014 Accepted: 16 March 2015

Published online: 10 June 2015

\section{References}

1. Hardy J, Selkoe DJ. The amyloid hypothesis of Alzheimer's disease: progress and problems on the road to therapeutics. Science. 2002;297:353-6. A published erratum appears in. Science. 2002;297:2209.

2. Salloway S, Mintzer J, Weiner MF, Cummings JL. Disease-modifying therapies in Alzheimer's disease. Alzheimers Dement. 2008;4:65-79.

3. De Strooper B, Saftig P, Craessaerts K, Vanderstichele H, Guhde G, Annaert $W$, et al. Deficiency of presenilin-1 inhibits the normal cleavage of amyloid precursor protein. Nature. 1998;391:387-90.

4. Green RC, Schneider LS, Amato DA, Beelen AP, Wilcock G, Swabb EA, et al. Effect of tarenflurbil on cognitive decline and activities of daily living in patients with mild Alzheimer disease: a randomized controlled trial. JAMA. 2009;302:2557-64.

5. Dockens R, Wang JS, Castaneda L, Sverdlov O, Huang SP, Slemmon R, et al. A placebo-controlled, multiple ascending dose study to evaluate the safety, pharmacokinetics and pharmacodynamics of avagacestat (BMS-708163) in healthy young and elderly subjects. Clin Pharmacokinet. 2012;51:681-93.
6. Coric V, van Dyck CH, Salloway S, Andreasen N, Brody M, Richter RW, et al. Safety and tolerability of the $\mathrm{\gamma}$-secretase inhibitor avagacestat in a phase 2 study of mild to moderate Alzheimer disease. Arch Neurol. 2012;69:1430-40.

7. Bateman RJ, Siemers ER, Mawuenyega KG, Wen G, Browning KR, Sigurdson WC, et al. A $\gamma$-secretase inhibitor decreases amyloid- $\beta$ production in the central nervous system. Ann Neurol. 2009;66:48-54.

8. Barten DM, Meredith Jr JE, Zaczek R, Houston JG, Albright CF. y-secretase inhibitors for Alzheimer's disease: balancing efficacy and toxicity. Drugs R D. 2006;:87-97.

9. De Strooper B, Annaert W, Cupers P, Saftig P, Craessaerts K, Mumm JS, et al. A presenilin-1-dependent $\gamma$-secretase-like protease mediates release of Notch intracellular domain. Nature. 1999;398:518-22.

10. Doody RS, Raman R, Farlow M, Iwatsubo T, Vellas B, Joffe S, et al. A phase 3 trial of semagacestat for treatment of Alzheimer's disease. N Engl J Med. 2013;369:341-50.

11. Folstein MF, Folstein SE, McHugh PR. "Mini-mental state": a practical method for grading the cognitive state of patients for the clinician. J Psychiatr Res. 1975;12:189-98.

12. McKhann G, Drachman D, Folstein M, Katzman R, Price D, Stadlan EM. Clinical diagnosis of Alzheimer's disease: report of the NINCDS-ADRDA Work Group under the auspices of Department of Health and Human Services Task Force on Alzheimer's Disease. Neurology. 1984;34:939-44.

13. Yesavage JA, Brink TL, Rose TL, Lum O, Huang V, Adey M, et al. Development and validation of a geriatric depression screening scale: a preliminary report. J Psychiatr Res. 1982-1983;17:37-49.

14. Mohs RC, Knopman D, Petersen RC, Ferris SH, Ernesto C, Grundman M, et al. Development of cognitive instruments for use in clinical trials of antidementia drugs: additions to the Alzheimer's Disease Assessment Scale that broaden its scope. The Alzheimer's Disease Cooperative Study. Alzheimer Dis Assoc Disord. 1997;11:S13-21.

15. Hollander M, Wolfe DA. Nonparametric statistical methods. New York: Wiley; 1973

16. The R Project for Statistical Computing. http://www.r-project.org/. Accessed 30 Mar 2015.

17. Fleisher AS, Raman R, Siemers ER, Becerra L, Clark CM, Dean RA, et al. Phase 2 safety trial targeting amyloid $\beta$ production with a $\gamma$-secretase inhibitor in Alzheimer disease. Arch Neurol. 2008;65:1031-8.

18. Mollenhauer B, Bibl M, Trenkwalder C, Stiens G, Cepek L, Steinacker P, et al. Follow-up investigations in cerebrospinal fluid of patients with dementia with Lewy bodies and Alzheimer's disease. J Neural Transm. 2005;112:933-48.

19. Eli Lilly. Lilly halts development of semagacestat for Alzheimer's disease based on preliminary results of phase III clinical trials: decision does not affect other Lilly Alzheimer's compounds in development [17 Aug 2010 press release]. https://investor.lilly.com/releasedetail.cfm?releaseid=499794. Accessed 30 Mar 2015

20. Bristol-Myers Squibb. Statement on avagacestat development status [30 Nov 2012 press release]. http://www.bms.com/news/features/2012/ Pages/AvagacestatDevelopmentStatus.aspx. Accessed 30 Mar 2015.

21. Martone RL, Zhou H, Atchison K, Comery T, Xu JZ, Huang X, et al. Begacestat (GSI-953): a novel, selective thiophene sulfonamide inhibitor of amyloid precursor protein $\gamma$-secretase for the treatment of Alzheimer's disease. J Pharmacol Exp Ther. 2009;331:598-608.

22. Chávez-Gutiérrez L, Bammens L, Benilova I, Vandersteen A, Benurwar M, Borgers $M$, et al. The mechanism of $\gamma$-secretase dysfunction in familial Alzheimer disease. EMBO J. 2012;31:2261-74.

\section{Submit your next manuscript to BioMed Central and take full advantage of:}

- Convenient online submission

- Thorough peer review

- No space constraints or color figure charges

- Immediate publication on acceptance

- Inclusion in PubMed, CAS, Scopus and Google Scholar

- Research which is freely available for redistribution 